\title{
Multiple sexual signals: calls over colors for mate attraction in an aposematic, color-diverse poison frog
}

\author{
Corinna E. Dreher* and Heike Pröhl \\ Institute of Zoology, University of Veterinary Medicine Hannover, Foundation, Hannover, Germany
}

\section{Edited by:}

Peter Schausberger, University of Natural Resources and Life

Sciences, Austria

Reviewed by:

Eduardo S. A. Santos, Universidade de São Paulo, Brazil

Martine Maan, University of

Groningen, Netherlands

*Correspondence:

Corinna E. Dreher, Institute of Zoology, University of Veterinary Medicine Hannover, Foundation, Bünteweg 17,

Hannover 30559, Germany e-mail: corinnadreher@gmail.com

Sexual signals indicate species identity and mate quality, and their importance for mate attraction is largely recognized. Recently, research in animal communication has started to integrate multiple signal modalities and evaluate their interactions. However, mate choice experiments across animal taxa have been limited to laboratory conditions, and assessments of multiple sexual signals under field conditions are still lacking. We take advantage of the divergence in visual and acoustic signals among populations of the Neotropical poison frog Oophaga pumilio to evaluate the importance of male advertisement calls and color patterns in female mate selection. Previous mate choice experiments in this species suggested color-assortative female mate preferences across many populations. Nevertheless, acoustic signals are crucial for sexual selection in frogs, and males of $O$. pumilio use advertisement calls to attract females. We hypothesize that both advertisement calls and coloration affect female mate selection in O.pumilio. To test this hypothesis we tested 452 receptive females from six populations in Costa Rica and Panama in their natural home ranges for preferences regarding local vs. non-local advertisement calls and color patterns. Overall, the calls overrode the effect of coloration, whereby most females preferred local over non-local calls. We found a tendency to prefer brighter (but not necessarily local) males in two populations. Furthermore, the strength of preferences varied geographically, and thus might be involved in prezygotic isolation among populations. The stronger effect of calls on mate attraction is associated with acoustic divergence between genetic groups in the species, while color pattern diversity is mostly located within one genetic group, i.e., not linked to large-scale population structure. Finally our data highlights the importance to consider an array of signal modalities in multiple wild populations in studies of behavioral isolation.

Keywords: sexual selection, multiple sexual signals, mate choice, prezygotic isolation, playback experiments, poison frogs

\section{INTRODUCTION}

A prerequisite for speciation to proceed is ongoing diversification (phenotypically or genetically) between different groups in a single species. Diversification can be promoted by natural selection (e.g., predation pressure), sexual selection or genetic drift (Panhuis et al., 2001; Sobel et al., 2010; Butlin et al., 2012) and their interactions, while habitat heterogeneity and geographic isolation generally contribute to trait divergence (Rundle and Nosil, 2005; Maan and Seehausen, 2011). All agents of diversification also affect sexual signals, like mating calls or color patterns, which are important for intrasexual communication and mate selection (Uy et al., 2009). Divergence in male sexual signals acting in concert with female preferences may lead to assortative mate-choice, which triggers (incomplete) reproductive isolation and constrains gene flow between diverging subpopulations or incipient species (Panhuis et al., 2001; Maan and Seehausen, 2011). Strong preferences for certain signals can ultimately cause complete prezygotic behavioral isolation and generate new species. Prezygotic or behavioral isolation seems to evolve earlier and induce the speciation process, and might contribute more to reproductive isolation than postyzgotic isolation (Coyne and Orr, 2004; Butlin et al., 2012). For example, acoustic signals in insects, birds, and anuran species are involved in assortative mate choice, causing prezygotic isolation between genetically divergent populations or incipient species (Wilkins et al., 2013).

Mate choice is a complex task and decisions are often based on multiple sexual traits of one or different sensory modalities (Ptacek, 2000; Candolin, 2003; Taylor et al., 2007). Recently, studies investigating the influence of sexual traits on mate choice have moved to an integrated approach, incorporating signals of different modalities (e.g., visual, acoustic, behavioral, chemical) to study the interactions between signals and their importance for mate choice and sexual selection (Kodric-Brown and Strecker, 2001; Candolin, 2003; Partan and Marler, 2005). The two most common forms of interactions between traits are (a) the sequential (hierarchical) use of different traits and (b) multiplicative interactions (both signals are required, reinforce, or deplete each other) (Candolin, 2003). Several studies in birds show that visual and acoustic signals are used in a sequential order, with visual traits being more important than acoustic signals for male aggression and mate choice (Ratcliffe and Grant, 1985; Uy et al., 2009). Whereas for two anuran species, Bombina orientalis (Zeyl and Laberge, 2011) and Allobates femoralis (Narins 
et al., 2003; De Luna et al., 2010), both acoustic and visual signals are necessary to evoke a behavioral response in conspecifics; thus, the interactions are multiplicative. The importance of multimodal signals for prezygotic isolation is well investigated in fish in laboratory experiments. In the Cyprinodon species complex mate selection in two sympatric species was found to be either affected by visual and olfactory cues or by olfactory cues alone (Kodric-Brown and Strecker, 2001). For Pundamilia nyererei acoustic signals alone did not induce phonotactic response in females, however presentation of acoustic signals reinforced preferences for visual stimuli (Estramil et al., 2013). These studies indicate, how different species may use single or multiple cues of different modalities for mate selection. However, research assessing the importance of multiple traits for sexual selection in the context of prezygotic isolation in the wild is scarce.

The Neotropical poison frog species Oophaga pumilio is distributed across the Caribbean slope of Nicaragua, Costa Rica, and Panama and has diverged into two genetic groups, a Northern group and a Southern group (Hauswaldt et al., 2011). Panamanian populations belong to the Southern genetic group, while Costa Rican and Nicaraguan populations belong to the Northern genetic group (hereafter called Southern and Northern genetic groups). The species shows considerable divergence in both body coloration (Daly and Myers, 1967) and acoustic signals (Prohl et al., 2007) among geographically separated populations. Color morph variability is mainly located at the Bocas del Toro Archipelago and adjacent mainland in Panama (Southern genetic group, Figure 1), despite the recent formation of the Archipelago in the last 10,000 years (Summers et al., 1997). The

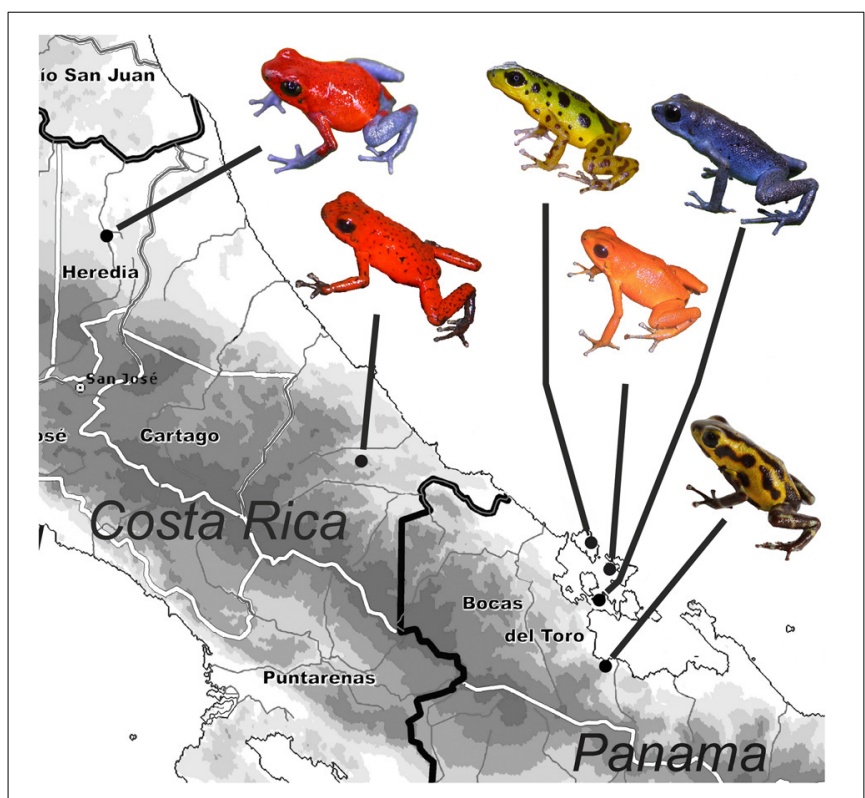

FIGURE 1 | Geographic distribution of the studied populations of $O$. pumilio in Costa Rica (Sarapiquí: red with blue legs; Hitoy: red morph) and Panama (Mainland: Río Gloria: yellow-black morph; Tierra Oscura: blue morph; Islands: Isla Colón: green-black morph; Isla Solarte: orange morph) with one representative frog for each population. aposematic coloration of this toxic species has been shown to be involved in sexual selection. In previous studies, female strawberry poison frogs were tested for their preference for males with local coloration or spotting pattern in mate choice experiments under laboratory conditions. The results showed that females prefer their local color morphs in some but not all populations (Summers et al., 1999; Reynolds and Fitzpatrick, 2007; Maan and Cummings, 2008). These studies were highly important to identify general female preferences for diverging visual sexual signals. However, previous studies neglected the impact of acoustic signals although advertisement calls are involved in mate or species recognition in almost all anuran amphibians (Ryan and Rand, 1993; Gerhardt and Huber, 2002). In strawberry poison frogs most variation in advertisement calls resides between the Northern and Southern genetic groups (Prohl et al., 2007). If both visual and acoustic traits are subject to female preference in strawberry poison frogs, assortative mate choice based on multimodal traits could restrict gene exchange between populations or genetic groups and promote the evolution of prezygotic isolation. Here we integrate visual and acoustic signals to identify the contributions of these signals for mate recognition under natural conditions. Hereby we aim to identify the role of sexual selection for progressive divergence in these traits, which may cause prezygotic reproductive isolation and facilitate speciation.

Given the presented theory and earlier findings we hypothesize that (1) both advertisement calls and colors should impact mate selection in strawberry poison frogs; (2) female preference functions may vary among populations, because divergence in traits may be affected by natural selection as well. Populations of the Northern genetic group (were calls vary substantially among populations) may show particular preferences for calls, while populations of the Southern genetic group may pay more attention to colors; (3) presentation of advertisement calls should be sufficient to induce an approach of receptive females to the loudspeaker (as in natural situations calling males may be hidden behind obstacles in the habitat); (4) potential preferences for local calls should be enhanced by presentation of a model frog of local coloration, while interchange of local and non-local frog models should mitigate preferences; (5) presenting the same sound on both sides, we expect females to show preferences for the local model.

To address these issues we conducted playback experiments to test female preferences for local and non-local traits in two populations of the Northern genetic group and four populations of the Southern genetic group (Figures 1, 2). Assuming that (i) the complexity of the tropical habitat of strawberry poison frogs, in which both sexes possess large territories or home ranges (Prohl and Berke, 2001; Meuche et al., 2011), has consequences for female choice behavior, and that (ii) preferences found under laboratory conditions do not necessarily coincide with preferences in natural situations (Gerhardt, 1982; Dyson and Passmore, 1988) we tested females directly in their natural habitat. Furthermore, we tested only females that were found in courtship with males to assure that their choice was related to mate selection. By testing receptive females directly in their home ranges we created experimental choice settings mimicking natural mate choice situations. 


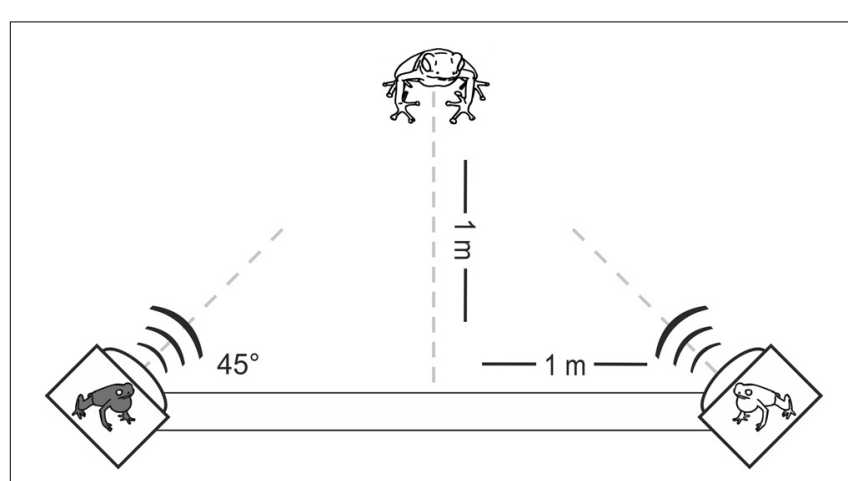

FIGURE 2 | Experimental setup for two-choice playback experiments. Model frogs positioned on top of the loudspeakers were only present in bimodal experiments (experiments III-V; Figure 3).
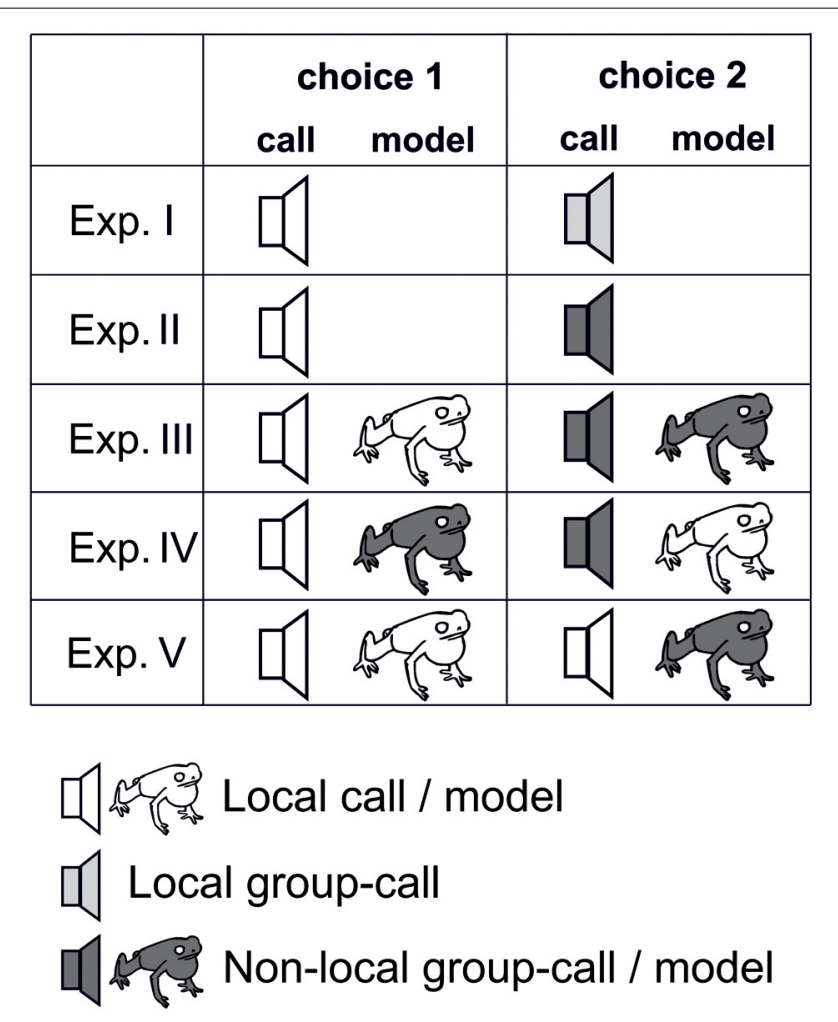

FIGURE 3 | Experimental types used for playback experiments. Type I and II unimodal experiments with different call sequences (indicated by loudspeaker symbol) on both sides; type III-V bimodal experiments with different combinations of call sequences and local and non-local model frogs (indicated by frog symbol). (White, local call/ local model; light gray, local group call; dark gray, non-local group call/non-local model).

\section{MATERIALS AND METHODS STUDY SYSTEM}

Strawberry poison frogs are distributed across the Caribbean slope of Central America in tropical lowland forests. The frogs are abundant, diurnal, and both sexes are territorial and provide parental care. Since female care is more time-intensive than male care, the operational sex ratio is male biased (Prohl, 2002) and females have been observed to be choosy about their mates (Prohl and Hodl, 1999). Once initiated courtship, females seem to abandon courting males occasionally ( $<20 \%$ of courtships) (Prohl and Hodl, 1999; Meuche et al., 2013). The species shows a complex phylogenetic history with admixture between evolving lineages and former dispersion of frogs from Northern populations into the South (Hauswaldt et al., 2011; Galindo Uribe et al., in review). Within the species two recent genetic groups have been identified: microsatellite analyses roughly assign Costa Rican populations to a Northern group and Panamanian populations to a Southern group (Hauswaldt et al., 2011). Advertisement calls of males, which are used to attract females and defend territories against intruders, vary in all call parameters among populations and between the two genetic groups (Prohl et al., 2007). The frogs are toxic and mostly aposematically colored. Throughout Costa Rica and in some Panamanian locations, strawberry poison frogs have a bright red coloration, while in the province of Bocas de Toro, Panama, an extremely diverse series of mostly non-syntopic color morphs on different island and mainland localities has evolved, with coloration ranging from cryptic green, over blue, black-white to conspicuous orange or yellow populations (Daly and Myers, 1967; Summers et al., 2003).

\section{STUDY SITES AND DURATION OF FIELD STUDY}

We conducted mate-choice experiments in six populations. Two populations were located in Costa Rica and belong to the Northern genetic group (Sarapiqui: $10^{\circ} 28.227^{\prime} \mathrm{N}$; $84^{\circ} 0.553$ 'W; 44 m.a.s.l. and Hitoy Cerere: $9^{\circ} 37.819^{\prime} \mathrm{N} ; 83^{\circ} 0.879^{\prime} \mathrm{W}$; 270 m.a.s.l.) and four were located in Panama and belong to the Southern genetic group. Two Panamanian populations were located on the mainland (Rio Gloria: $8^{\circ} 59.100^{\prime} \mathrm{N}$; $82^{\circ} 13.916$ 'W; 24 m.a.s.l. and Tierra Oscura: $9^{\circ} 11.776^{\prime} \mathrm{N} ; 82^{\circ} 14.976^{\prime} \mathrm{W}$; 7 m.a.s.l.) and two on different islands (Colón: $9^{\circ} 23.170{ }^{\prime} \mathrm{N}$; $82^{\circ} 15.941^{\prime}$ W; 35 m.a.s.l. and Solarte: $9^{\circ} 19.946^{\prime} \mathrm{N} ; 82^{\circ} 12.939$ 'W; 4 m.a.s.l.). Mate Choice experiments were conducted in three study periods, lasting from August 2008 to December 2009, from April 2010 to November 2010 and from April 2011 to October 2011. During this time we tested a total amount of 452 different receptive females for their mate preferences.

\section{MATE CHOICE EXPERIMENTS}

Playback experiments (see Meuche et al., 2013) were conducted between 6 am and $5 \mathrm{pm}$, with most of the experiments taking place during the morning hours when courtship activity was at its peak. In preliminary experiments we found that only females showing courtship behavior toward a male responded to and approached sexual signals (call sequences emitted via loudspeakers and model frogs of different coloration). Therefore, we selected courting females that followed a calling male and interacted with him for the experiments to assure that the females' response to visual and acoustic signals was related to mate choice. That courting females were receptive was furthermore corroborated by the fact that most of these females (87\%) lost unfertilized eggs when held in captivity until the next day after the experiments, while non-courting females never laid eggs. Before starting playback-experiments with receptive females the male of the 
couple, as well as males calling in the immediate vicinity, were captured to avoid interference.

To generate the acoustic signals we analyzed 2930 advertisement call sequences from 293 males of 23 different populations of strawberry poison frogs of the Northern and Southern genetic group (Prohl et al., 2007). We analyzed five call parameters (dominant frequency, call rate, call duration, duty cycle, and pulse rate), adjusted them for temperature and calculated average values for each population and the two genetic groups (see Table S1 in Supporting Information). Out of the recorded call sequences we chose the call that fitted the average values of dominant frequency, call duration, and pulse rate best. We then added a silent interval of a population-specific duration to create call sequences with the required call rate and duty cycle. By amplification of the selected call with its specific silent interval we generated call sequences for each population ("local calls") and for both genetic groups ("Southern group call" and "Northern group call") (see Table S1).

These sound sequences were used in two-choice playbackexperiments. In five experiments we tested receptive female strawberry poison frogs for their preferences for unimodal or bimodal signals. In experiments I and II females had to choose from two call sequences (Figure 3; experiments I and II), and in three further experiments we used bimodal stimuli, combining two calls with two plasticine model frogs of different color patterns (see Figure 3; experiments III-V; and Figure S1). Experiment I tested for female preferences when the local call was presented against the average call of the local genetic group ("local group call"). Experiment II presented the local call against the average call of the non-local genetic group ("non-local group call"). The remaining experiments used bimodal stimuli, presenting the calls in combination with two model frogs painted to mimic the local and a non-local color morph (see Figure S1). Experiment III presented the local call in combination with the local model on one side vs. the non-local group call with the non-local model on the other side. In Experiment IV the model frogs were switched, (combining local call/non-local model and non-local group call/local model). For Experiment V both loudspeakers broadcast the local call in combination with one of the two different model frogs (Figure 3). We tested a minimum of 15 receptive females in each of the five experiments in each population, resulting in a total of 452 different females. To assure that each female was tested only once-and to avoid problems with pseudoreplicationphotographs were taken and we applied toe-clipping where no individual spotting pattern allowed identification of the females. The study was conducted in accordance with German, Costa Rican, and Panamanian laws and followed the "Guidelines for the treatment of animals in behavioral research and teaching" and the "Guidelines for use of live amphibians and reptiles in field research."

During the playback experiments the calls were presented via Apple ${ }^{\circledR}$ Ipods $^{\circledR}$ and loudspeakers (Visaton FRS $10 \mathrm{WP}$ ), which were connected to an amplifier (Basetech AP-2100 MiniVerstärker) and a $12 \mathrm{~V}$ battery. The loudspeakers were fixed at the ends of a wooden plank at an angle of $45^{\circ}$, ensuring that the calls were broadcast toward the female when the middle of the plank was placed at a distance of $1 \mathrm{~m}$ from the receptive female before starting the experiment (Figure 2). The sound pressure level in both loudspeakers was set to $72 \mathrm{~dB}$ at a distance of $50 \mathrm{~cm}$, which corresponds to the average natural sound pressure level of advertisement calls at this distance. The experimental setup was examined for linear presentation of the frequency range of the frogs' advertisement calls: power spectra of the playback calls resembled natural calls up to $10 \mathrm{kHz}$. For experiments with bimodal stimuli, we used handmade plasticine model frogs, which were modeled with STAEDTLER ${ }^{\circledR}$ Fimo $^{\circledR}$, hardened in an oven and later painted with acrylic paint. To mimic the brilliance of living frogs, we applied a layer of clear coat on the painted models. In bimodal experiments, two model frogs (one local model and one non-local model) were placed on top of the loudspeakers since males usually call from elevated perches. The criterion for the selection of the alternative model presented in experiments with bimodal stimuli, was to be substantially different in coloration from the local model. Since red populations are prevalent in this species, we always combined one red model with one nonred model. In red populations we combined the local red model with green or yellow models (Figure S1).

Upon approaching one loudspeaker to a distance less than $20 \mathrm{~cm}$, which took on average between $29 \mathrm{~min}$ and $1: 15 \mathrm{~h}$ in different populations, the female was considered to have a preference for this choice and the female was captured. We selected $20 \mathrm{~cm}$ as cut-off distance because male $O$. pumilio stay stationary and emit advertisement calls until the female gets into close proximity. At these distances $(\sim 20-30 \mathrm{~cm})$ the males orient toward and approach the female and start to interact with it. During close-range interactions males switch from advertisement calls to courtship calls. With this experimental procedure we intended to cover the mate attraction phase in which both signalsadvertisement calls and colors-could be perceived and evaluated by the female in a natural situation. At larger distances the visual signals is probably not perceptible while at closer distances the very low courtship calls replace the advertisement calls.

For several reasons we decided to use model frogs instead of live males in our experiments. In preliminary experiments we found receptive females to pay equal attention to model frogs and live male frogs kept under a daylight transparent glass. Conducting the experiments with live males, we expected the following problems: (1) the behavior of a male during courtship can influence the preference of the female in mate choice experiments (Andersson, 1994; Wong et al., 2011) and we could not control for motivation of a male to court females of local or non-local origin, including calling behavior (with vocal-sac inflation probably acting as an additional visual cue); (2) advertisement calls emitted by living males interfere with presentation of local or non-local sound sequences and (3) we could not control for body or vocal sac size of the animals (average weight of males differs between 0.38 and $0.99 \mathrm{~g}$ among study populations).

\section{DATA ANALYSIS}

We conducted global binomial tests to test for preferences in each experiment. For this analysis we included the results of all investigated populations $(\mathrm{N} \approx 90$ females per experiment). Furthermore, we applied binomial tests to analyze general preferences in each genetic group (North: $\mathrm{N} \approx 30$, South: $\mathrm{N} \approx 60$ 
females per experiment). To test for population specific preferences, we applied binomial tests to analyze preferences in each experiment separately for each of the six populations. All binomial tests were conducted with IBM $^{\circledR}$ SPSS.

To test if presentation of assorted or interchanged model frogs affects preferences in females, we used Generalized Linear Models (GLMs) for pairwise comparisons. We tested if results of the following pairs of experimental types deviated significantly from each other: Experiments I and II (are preferences for the local call more pronounced when tested against the non-local group call or the local group call?); Experiments II and III (are preferences more pronounced when calls are combined with the respective models?); Experiments II and IV (are preferences for calls altered when calls are combined with non-local models?); Experiments III and IV (are there differences in the results depending on the position of the models?) and Experiments III and V (are preferences for the local call/local model combination altered, when the non-local model is also presented with the local call?). These pairwise comparisons were conducted on species, group, and population levels. Depending on the size of the data sets, GLMs were conducted assuming quasi-binomial or binomial error distributions. All GLMs were conducted with R (R Developmental Core Team, 2012).

\section{RESULTS}

All statistical tests were conducted at the species level (all females included in the analysis, $\mathrm{N} \approx 90$ females per experiment), group level (all females in a single genetic group included in the analysis, Northern group: $\mathrm{N} \approx 30$ females, Southern group $\mathrm{N} \approx 60$ females per experiment), and population level $(\mathrm{N} \approx 15$ females for each experiment) (see Table $\mathbf{1}$ ).

\section{FEMALE PREFERENCES FOR LOCAL vS. NON-LOCAL CALLS AND COLORATION}

In experiment I female strawberry poison frogs did not discriminate between the local call and the local group call on species, group or population level (see Figures 4, 5 and Table 1). However, in experiment II we found a highly significant preference for the local call over the non-local group call on species and group level and in nearly all populations. This preference was also present when the calls were presented together with either matching or non-matching model frogs (experiments III and IV). No preference was found for either the local or the non-local color morph at any level (see Figures 4, 5 and Table 1).

Females in the two genetic groups differed in their preferences for sexual signals. In the Southern genetic group, females showed a highly significant preference for the local call when presented against the non-local group call, independent of the presentation or assignment of model frogs (see Table 1; experiments II-IV). However, in the Northern genetic group, the acoustic signal did not override the effect of the visual signal as clearly as in the Southern genetic group. Though females of the Northern genetic group also showed a preference for the local call when presented against the non-local group call (experiment II), this preference was no longer significant when the calls were presented with either matching (experiment III) or non-matching model frogs (experiment IV). When broadcasting the local call on both sides

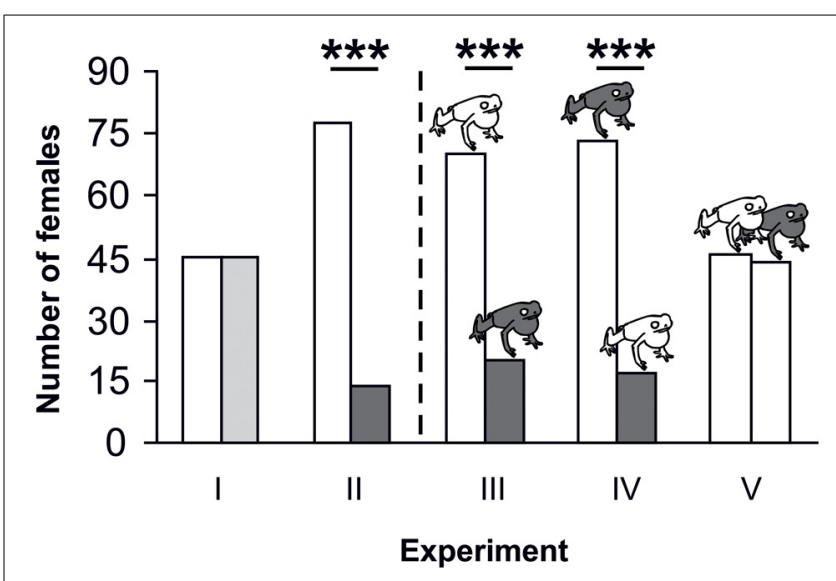

FIGURE 4 | Global results of playback experiments for all tested populations. The bars present the number of females which selected one or the other signal or signal combination. Bar coloration indicates call type, model frog coloration indicates model type presented in the experiments (white, local call/local model; light gray, local group-call; dark gray, non-local group-call/ non-local model). Asterisks indicate significant preferences for one choice over the other (*** $P<0.001$; Table 1).

Table 1 | Results ( $P$-values) of binomial tests including sample sizes $(N)$.

\begin{tabular}{|c|c|c|c|c|c|}
\hline & Experiment I & Experiment II & Experiment III & Experiment IV & Experiment V \\
\hline O. pumilio & $1.000(92)$ & $0.000(90)$ & $0.000(90)$ & $0.000(90)$ & $0.916(90)$ \\
\hline North & $0.585(31)$ & $0.003(30)$ & $0.362(30)$ & $0.099(30)$ & $0.585(30)$ \\
\hline Sarapiqui & $0.302(16)$ & $0.210(15)$ & $1.000(15)$ & $0.302(15)$ & 1.000 (15) \\
\hline Hitoy Cerere & 1.000 (15) & $\mathbf{0 . 0 0 7}(15)$ & $0.302(15)$ & $0.302(15)$ & 0.607 (15) \\
\hline South & $0.699(61)$ & $0.000(60)$ & $0.000(60)$ & $0.000(60)$ & $0.897(60)$ \\
\hline Rio Gloria & $0.607(16)$ & $\mathbf{0 . 0 0 1}(15)$ & 0.118 (15) & $0.001(15)$ & $0.118(15)$ \\
\hline Tierra Oscura & 0.607 (15) & $0.001(15)$ & $0.001(15)$ & $0.001(15)$ & $0.118(15)$ \\
\hline Colón & 0.607 (15) & $0.035(15)$ & $0.001(15)$ & $0.035(15)$ & 0.607 (15) \\
\hline Solarte & $0.302(15)$ & $\mathbf{0 . 0 0 7}(15)$ & $\mathbf{0 . 0 0 7}(15)$ & $\mathbf{0 . 0 0 7}(15)$ & $0.302(15)$ \\
\hline
\end{tabular}

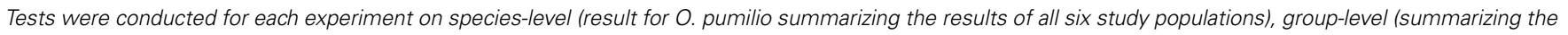

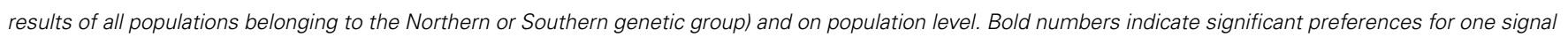
combination. 


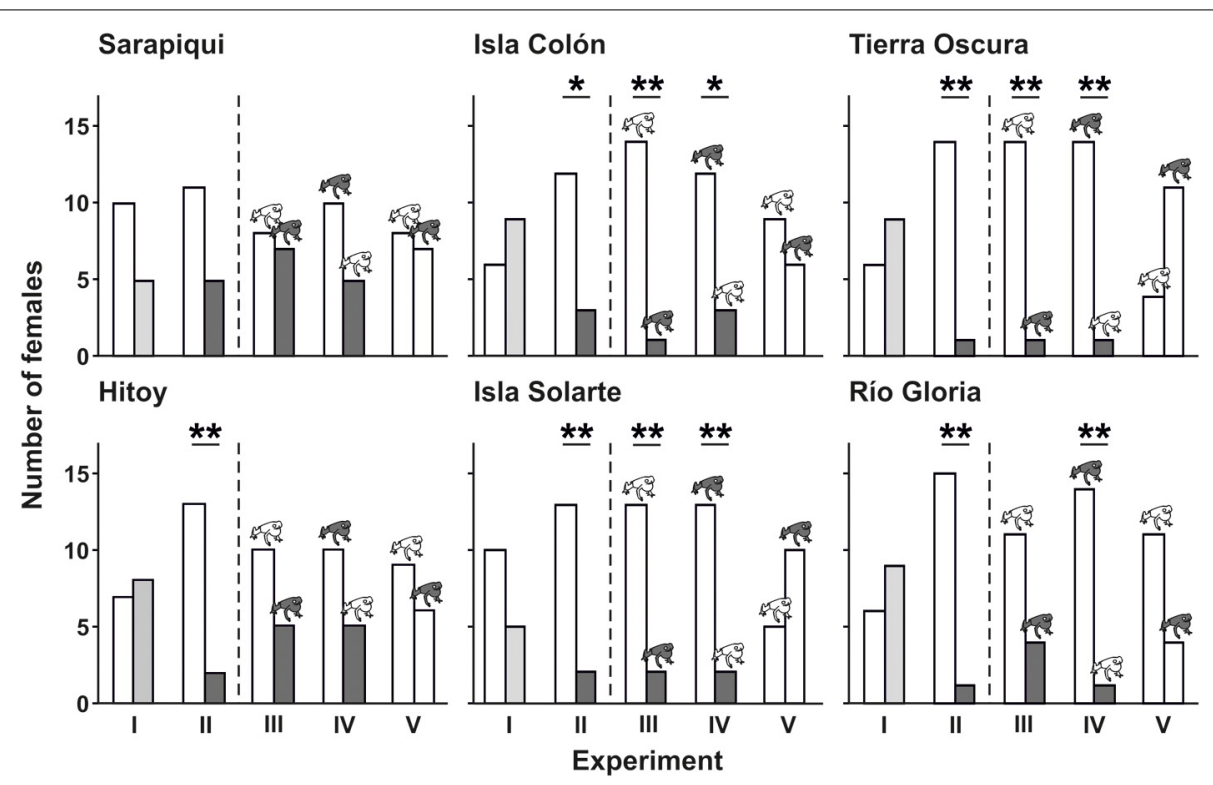

FIGURE 5 |Results of playback experiments for each population. The bars present the number of females which selected one or the other signal or signal combination. Bar coloration indicates call type, model frog coloration indicates model type presented in the experiments (white, local call/local model; light gray, local group-call; dark gray, non-local group-call/non-local model). Preferences for one choice over the other are indicated with asterisks $(* P<0.05$; ** $P<0.01$; Table 1) (experiment $\mathrm{V}$ ) in combination with a local or non-local model, we did not find significant preferences for any presented model in either genetic group (see Figure 5 and Table 1).

Furthermore, females of different populations in the Northern genetic group differed in their responses to sexual signals. Frogs from the Sarapiquí population did not show a significant preference for any of the signals or signal combinations. In contrast, females from Hitoy Cerere significantly preferred the local call over the non-local group call, but only when presented without model frogs (experiment II) (see Figure 5 and Table 1). In the Southern genetic group, females from most populations preferred the local call when presented against the non-local group call, independent of the presence and allocation of model frogs (experiments II-IV). In two populations of the Southern genetic group, 11 out of 15 females preferred one of the color morphs over the other when both were combined with the local call: at Río Gloria 11 females chose the local (yellow) color morph, while only four chose the non-local (red) morph. In Tierra Oscura we found the opposite pattern: 11 females selected the non-local (red) morph and 4 females selected the local (blue) color morph. Even though these results point to preferences for colors (73 vs. $27 \%$ choices) the results were not significant (see Figure 5 and Table 1).

For additional information about the behavior of females after approaching the loudspeakers to a distance of $20 \mathrm{~cm}$ please see Supplementary Information 1.

\section{DIFFERENCES IN FEMALE BEHAVIOR BETWEEN EXPERIMENTS Experiments I and II}

Are preferences for the local call more pronounced when tested against the non-local group call than against the local group call?At the species level, for the Southern genetic group as well as for
Tierra Oscura and Rio Gloria, the results of experiments I and II were significantly different, i.e., females discriminated significantly against the non-local group call, but not the average call of their own genetic group (see Table 2).

\section{Experiments II and III}

Are preferences more pronounced when calls were combined with the respective models?-None of the pairwise comparisons was significant, i.e., the preferences for the local calls were not enhanced by a combination with a model frog of the local coloration (see Table 2).

\section{Experiments II and IV}

Are preferences for calls altered when calls are combined with non-local models? - None of the pairwise comparisons was significant, i.e., the preference for the local call was not affected by a combination with a non-local color morph (see Table 2).

\section{Experiments III and IV}

Are there differences in the results depending on the position (matching or non-matching) of the models?-The presence of a model of the local vs. the non-local color morph did not affect the preference for the local call in any of the comparisons (see Table 2).

\section{Experiments III and V}

Are preferences for the local call and local model combination (vs. non-local group-call and non-local model) still present when the alternative choice consists of the same local call combined with the non-local model?-The results of experiments III and V were significantly different at the species level, for the Southern genetic group as well as for Solarte and Tierra Oscura, i.e., the choice of females did depend on the call the non-local model was presented with (see Table 2). 
Table 2 | Results ( $P$-values) of pairwise comparisons among different experiments including test statistics (z-values) in italics.

\begin{tabular}{|c|c|c|c|c|c|}
\hline & \multicolumn{5}{|c|}{ Experiments } \\
\hline & I and II & II and III & II and IV & III and IV & III and V \\
\hline \multirow[t]{2}{*}{ O. pumilio } & 0.001 & 0.780 & 0.969 & 0.980 & 0.015 \\
\hline & -3.829 & -0.945 & -0.504 & 0.446 & -2.954 \\
\hline \multirow[t]{2}{*}{ North } & 0.143 & 0.264 & 0.662 & 0.929 & 0.995 \\
\hline & -2.086 & -1.780 & -1.141 & 0.655 & -0.321 \\
\hline \multirow[t]{2}{*}{ Sarapiqui } & 1.000 & 0.834 & 1.000 & 0.899 & 1.000 \\
\hline & -0.124 & -0.876 & -0.124 & 0.743 & 0.000 \\
\hline \multirow[t]{2}{*}{ Hitoy Cerere } & 0.112 & 0.570 & 0.570 & 1.000 & 0.989 \\
\hline & -2.182 & -1.259 & -1.259 & 0.000 & -0.378 \\
\hline \multirow[t]{2}{*}{ South } & 0.000 & 0.998 & 1.000 & 0.998 & 0.001 \\
\hline & -4.012 & -0.245 & 0.000 & 0.245 & -3.752 \\
\hline \multirow[t]{2}{*}{ Rio Gloria } & 0.037 & 0.4948 & 1.000 & 0.4948 & 1.000 \\
\hline & -2.621 & -1.369 & 0.000 & 1.369 & 0.000 \\
\hline \multirow[t]{2}{*}{ Tierra Oscura } & 0.036 & 1.000 & 1.000 & 1.000 & 0.009 \\
\hline & -2.621 & 0.000 & 0.000 & 0.000 & -3.072 \\
\hline \multirow[t]{2}{*}{ Colón } & 0.116 & 0.710 & 1.000 & 0.710 & 0.189 \\
\hline & -2.150 & 1.027 & 0.000 & -1.027 & -1.923 \\
\hline \multirow[t]{2}{*}{ Solarte } & 0.569 & 1.000 & 1.000 & 1.000 & 0.0268 \\
\hline & -1.259 & 0.000 & 0.000 & 0.000 & -2.739 \\
\hline
\end{tabular}

Bold numbers indicate significant differences among results of different experiments.

\section{DISCUSSION}

Mate choice decisions are crucial for the formation of isolation barriers among emerging lineages or species. Within the framework of prezygotic behavioral isolation the importance of different sexual traits is still understudied, especially under field conditions. In this study we conducted mate choice experiments in six natural populations belonging to two genetic groups across the distribution range of the strawberry poison frog. We demonstrate that (i) acoustic signals exceed visual signals in their importance for mate attraction across populations, and (ii) female preferences vary among populations and between genetic groups.

\section{NORTH vs. SOUTH}

Our 452 playback experiments reveal that preferences of females of the Northern genetic group are less pronounced than those of the Southern group; thus, behavioral isolation is asymmetric between the genetic groups. In the Southern genetic group, where divergence in call parameters is lower among populations (Prohl et al., 2007), we found a strong pattern of preference for the local call over the non-local group call, independent of the presence and assortment of the visual signal (coloration of model frogs). The Northern group call was less attractive for frogs from the Southern genetic group, while females from the Northern genetic group also chose the Southern group call but not as often as the local call. These differences in preferences could be due to a variety of reasons: For example, the Northern group call has a lower calling rate, which is known to be less attractive to female anurans (Sullivan et al., 1995; Gerhardt and Huber, 2002) (see Table S1).
On the other hand, asymmetrical behavioral isolation caused by differences in the strength of discrimination against heterospecific traits between lineages seems to be common in frogs (e.g., Hoskin et al., 2005) and other systems (Kodric-Brown and Strecker, 2001; Panhuis et al., 2001; Berdan and Fuller, 2012). Whether it corresponds to the strength of postzygotic isolation or hybrid fitness as found in some of these earlier studies is not known for strawberry poison frogs.

\section{IMPACT OF CALLS AND COLORS}

Pairwise comparisons showed that females discriminate between calls of different genetic groups but not among different calls of their own group (experiments I and II) (see Table 2), suggesting that call-based prezygotic isolation is present between genetic groups but absent among populations within genetic groups. Acoustic signals are involved in assortative mate choice and contribute to prezygotic isolation between incipient species or diverging populations across different animal taxa (e.g., Boul et al., 2007; Noh and Henry, 2009; Uy et al., 2009); therefore, this result is not surprising. More importantly, female preferences for local calls override the possible effect of model frog coloration in our experiments, since exchanging model frogs did not alter female preferences (experiments III and IV), whereas a change in the presented call did affect the results (experiments III and V). This indicates that for strawberry poison frogs, advertisement calls play a more important role in mate attraction than colors, and most females would probably not approach a male emitting the "wrong" call. However, strength of preferences varied among the two genetic lineages. In laboratory experiments investigating mate selection based on visual, olfactory and acoustic signals sympatric sister species of fish showed asymmetrical use of signals of different modalities: while Cyprinodon maya used a combination of visual and olfactory cues, Cyprinodon labiosus discriminated against heterospecifics based on olfactory cues alone (Kodric-Brown and Strecker, 2001). In one cichlid fish species, visual signals_-but not acoustic signals — alone were sufficient for mate attraction. Nevertheless, acoustic signals enhanced female preferences for males when visual signals were combined with conspecific sound (Estramil et al., 2013). Showing that the importance of signals of different modalities for prezygotic isolation might vary not only among sister species but even among populations of a single species, we consider the results of our study to be a valuable addition to existing studies of multimodal signaling.

Although our experiments did not reveal a general pattern of females to prefer the local or non-local color morphs, females among populations differed in their preferences respective to coloration. In experiments with local calls only (experiment V), females from Río Gloria showed a tendency to select the local yellow color morph over the alternative red color morph, while the blue Tierra Oscura females showed a tendency to select the brighter non-local red morph. Earlier studies of sexual selection in strawberry poison frogs recorded different patterns and degrees of color-assortative preferences in different populations (Summers et al., 1999; Reynolds and Fitzpatrick, 2007; Maan and Cummings, 2008). Furthermore, sexual dimorphism in brightness was detected in the population from the island Solarte, 
and experiments suggested sexual selection for brighter animals (Maan and Cummings, 2009) (Dreher et al. submitted). Preferences for brightness have been linked to superior health status in a number of studies (e.g., Milinski and Bakker, 1990) and/or may evoke greater sensory stimulation in the choosing sex (Maan and Cummings, 2009). Our findings are consistent with the idea that females prefer brighter males, since in both casesRio Gloria and Tierra Oscura-the preferred color morph was brighter than the alternative color morph, regardless of the origin (local or non-local) of the model frog (Dreher, unpublished data). These results might imply that the preference for brighter males is a widespread but not exclusive pattern in strawberry poison frogs.

In the Southern genetic group, in the region of Bocas del Toro populations vary in coloration and advertisement calls (Prohl et al., 2007). However, call variation is lower than in the Northern genetic group and variation of calls within the genetic group does not seem to affect female choice. Here, prezygotic isolation based on color-assortative mating might vary from week to strong depending on the characteristics and ecology of the involved populations (Maan and Cummings, 2008; Richards-Zawacki et al., 2012). For example, in several contact zones between populations of different colors, animals with intermediate color morphs can be observed (e.g., between red and black-white at Rio Cascaje on the Panamanian mainland). Hybridization among color morphs indicates that there is no complete reproductive isolation between different color morphs through color-assortative mating in this species. Taken together, the results of this and previous studies suggest that, when controlling for call variation, preferences for local or bright coloration range from strong and moderate to absent across the species distribution (Summers et al., 1999; Reynolds and Fitzpatrick, 2007; Maan and Cummings, 2008). Ecological correlates to the different patterns of female preferences (e.g., predation pressure, light conditions, level of divergence in coloration and brightness) need further attention. Polymorphic populations or contact zones where the sexes of different and intermediate morphs meet offer the opportunity to study the link between coloration, mate choice, and gene flow across natural populations.

Furthermore, our and earlier data imply that strawberry poison frogs use acoustic and visual cues in a sequential order, with advertisement calls used to attract potential mates and facilitate selection at a larger distance while visual cues might act later in courtship during close-range assessment. In natural populations, the distance between calling males is usually several meters (Prohl and Berke, 2001; Prohl and Ostrowski, 2011), which makes it difficult for females to assess the coloration of two or more males simultaneously, while the advertisement calls of frogs appear to be detectable and assessable from this distance. Receptive females have been observed to react to and approach a male calling from several meters away (Meuche et al., 2013). However, during the prolonged courtship of strawberry poison frogs, a female still has the chance to reject the male after entering the final stage of courtship (which includes direct tactile interaction between the sexes at the oviposition site) (Prohl and Hodl, 1999). During close-range assessment, coloration, courtship calls, and other behavioral traits of the male or the quality of the oviposition site could play a role for a female's decision. However, to date, there are no studies investigating the importance of this final courtship stage for female mate choice of strawberry poison frogs. As failure in long-distance attraction would impede the stage of close-range assessment our observations point to a higher importance of acoustic signals for mate choice in strawberry poison frogs.

\section{SEXUAL SIGNALS, GENETIC POPULATION STRUCTURE, AND SPECIATION IN OOPHAGA}

In O. pumilio, variation in the two sexual signals-calls and colors - is differently situated with respect to geography and genetic groups. The vast amount of color diversity is located within the Southern genetic group in a small geographic area in Panama while variation in calls is mainly located between the two genetic groups (Prohl et al., 2007; Wang and Shaffer, 2008; Hauswaldt et al., 2011). Hence, divergence in calls coincides with divergence in the genetic population structure within the species. In Panama, one other Oophaga species (O. vincentei) and one separated population of $O$. pumilio on Isla Escudo are genetically closely related to populations of $O$. pumilio from North Costa Rica (Hauswaldt et al., 2011). Several lineages (originating Southern O. pumilio, O. vincentei, and O. pumilio from Escudo) probably invaded Panama from the North approximately 2-1 million years ago (Galindo Uribe et al., in review). Differences in call properties among populations of Southern O. pumilio and other invading frogs might have prevented mating among genetically distinct animals to prevent hybridization. These circumstances could have contributed to the evolution of pronounced discrimination abilities of females from the Southern genetic group against nonlocal call attributes. To date, O. vincentei and O. pumilio from Escudo are bioacoustically clearly differentiated from all (other) O. pumilio populations (Jungfer et al., 1996).

We propose the following scenario for sexual signal divergence and associated preferences in strawberry poison frogs: The association between acoustic and genetic divergence suggests sexual selection as the main driver of acoustic divergence. Based on preferences for local calls, prezygotic isolation potentially impedes mating with genetically different males and thus decreases the risk of reproductive failure. This might have been relevant for the divergence between both genetic groups in strawberry poison frogs and among Oophaga species. In contrast, the evolution of color diversity appears to be the result of drift and natural selection (predation pressure) since it is coupled with divergence in toxicity and antipredator behavior (Prohl and Ostrowski, 2011; Maan and Cummings, 2012). Under that scenario the evolution of preferences for local or brighter coloration would have followed ecological adaptation, as previously found in several Heliconius species (e.g., Jiggins et al., 2001) and a number of other taxa (Rundle and Nosil, 2005).

Consistent with this idea, several closely related Oophaga species that occur in Costa Rica and Panama are clearly differentiated among each other by their advertisement calls (Prohl et al., 2013), and some of these species (e.g., O. granulifera and $O$. vincentei) also show color divergence among populations, mainly into red and green morphs (Brusa et al., 2013) (http://www.dendrobase.de/html/D_oophaga_vicentei.html). As in O. pumilio, color divergence is not related to genetic divergence in O. granulifera (Brusa et al., 2013). These complex patterns 
of call and color diversity within several dendrobatid species offer prospects to further evaluate the importance of different mechanisms of speciation mediated through different sensory channels. In the future, multimodal experiments could evaluate the effects of signals of different sensory channels on intraand intersexual selection. Unimodal and multimodal experiments using an array of intra- and interspecific signals might furthermore help to disentangle how signals of one or more modalities impacted divergence among incipient species.

\section{CONCLUSIONS}

Divergence in the sexual signals of one sex and associated preferences in the other sex contribute to prezygotic isolation, speciation and thus the evolution of species diversity. The complexity of the link between mate choice and speciation increases when several signal modalities - shaped by different evolutionary forces-are involved in mate selection. In the strawberry poison frog, advertisement calls have diverged between two genetic groups while variation in (aposematic) coloration is limited to populations within the Southern genetic group. Testing females for preferences for local or non-local calls and colorations, we found acoustic stimuli outpaced visual stimuli in female attraction. However, the strength of preferences varied between genetic groups. The results suggest that prezygotic isolation based on calls could contribute to ongoing divergence between the genetic groups. They also indicate that sexual signals vary in their relevance for mate attraction in the field, and divergence in coloration might contribute to sexual selection only in areas where color diversity had previously evolved. While our study concentrated on the relative importance of visual vs. acoustic signals, further studies should disentangle ecological factors that mediate variation in sexual behavior across species ranges.

\section{AUTHOR CONTRIBUTIONS}

Corinna E. Dreher and Heike Pröhl designed the experiments, Corinna E. Dreher performed the research, Corinna E. Dreher and Heike Pröhl analyzed the data and wrote the manuscript.

\section{ACKNOWLEDGMENTS}

We are grateful for the advice and comments of Beatriz Willink, Adolfo Amézquita, the two reviewers, and members of our research group on earlier versions of the manuscript. We thank Ivonne Meuche for advice and support on the playback setup and all students who helped with data collection in the field. We thank the local authorities in Costa Rica (MINAE) and Panama (ANAM) for approving the project and providing research permits throughout the years (Costa Rica: 119-2008SINAC, 231-2008-SINAC, 155-2009-SINAC, 115-2010-SINAC, 029-2011-SINAC; Panama: SE/A-44-08, SE/A-3-09, SE/A-59-10, SE/A-116-10, SE/A-17-11). We also thank P. Pallmann for advice in statistical procedures. The project was funded by the German Research Foundation DFG (PR 626/4-1 and PR 626/4-2).

\section{SUPPLEMENTARY MATERIAL}

The Supplementary Material for this article can be found online at: http://www.frontiersin.org/journal/10.3389/fevo. 2014.00022/abstract

\section{REFERENCES}

Andersson, M. (1994). Sexual Selection. Princeton, NJ: Princeton University Press. Berdan, E. L., and Fuller, R. C. (2012). A test for environmental effects on behavioral isolation in two species of killifish. Evolution 66, 3224-3237. doi: 10.1111/j.1558-5646.2011.01646.x

Boul, K. E., Funk, W. C., Darst, C. R., Cannatella, D. C., and Ryan, M. J. (2007). Sexual selection drives speciation in an Amazonian frog. Proc. Biol. Sci. 274 399-406. doi: 10.1098/rspb.2006.3736

Brusa, O., Bellati, A., Meuche, I., Mundy, N. I., and Prohl, H. (2013). Divergent evolution in the polymorphic granular poison-dart frog, Oophaga granulifera: genetics, coloration, advertisement calls and morphology. J. Biogeogr. 40, 394-408. doi: 10.1111/j.1365-2699.2012.02786.x

Butlin, R., Debelle, A., Kerth, C., Snook, R. R., Beukeboom, L. W., Cajas, R. F. C., et al. (2012). What do we need to know about speciation? Trends Ecol. Evol. 27, 27-39. doi: 10.1016/j.tree.2011.09.002

Candolin, U. (2003). The use of multiple cues in mate choice. Biol. Rev. 78, 575-595. doi: $10.1017 /$ s1464793103006158

Coyne, J. A., and Orr, H. A. (2004). Speciation. Sunderland, MA: Sinauer Associates.

Daly, J. W., and Myers, C. W. (1967). Toxicity of Panamanian poison frogs (Dendrobates): some biological and chemical aspects. Science 156, 970-973. doi: 10.1126/science.156.3777.970

De Luna, A. G., Hodl, W., and Amezquita, A. (2010). Colour, size and movement as visual subcomponents in multimodal communication by the frog Allobates femoralis. Anim. Behav. 79, 739-745. doi: 10.1016/j.anbehav.2009. 12.031

Dyson, M. L., and Passmore, N. I. (1988). Two-choice phonotaxis in Hyperolius marmoratus (Anura: Hyperoliidae): the effect of temporal variation in presented stimuli. Anim. Behav. 36, 648-652. doi: 10.1016/s0003-3472(88) 80146-5

Estramil, N., Bouton, N., Verzijden, M. N., Hofker, K., Riebel, K., and Slabbekoorn, H. (2013). Cichlids respond to conspecific sounds but females exhibit no phonotaxis without the presence of live males. Ecol. Freshwater Fish, n/a-n/a. doi: $10.1111 /$ eff.12081

Gerhardt, H. C. (1982). Sound pattern recognition in some north american treefrogs (Anura: Hylidae): implications for mate choice. Am. Zool. 22, 581-595.

Gerhardt, H. C., and Huber, F. (2002). Acoustic Communication in Insects and Anurans: Common Problems and Diverse Solutions. Chicago; London: University of Chicago Press.

Hauswaldt, J. S., Ludewig, A. K., Vences, M., and Prohl, H. (2011). Widespread co-occurrence of divergent mitochondrial haplotype lineages in a Central American species of poison frog (Oophaga pumilio). J. Biogeogr. 38, 711-726. doi: 10.1111/j.1365-2699.2010.02438.x

Hoskin, C. J., Higgie, M., McDonald, K. R., and Moritz, C. (2005). Reinforcement drives rapid allopatric speciation. Nature 437, 1353-1356. doi: 10.1038/nature04004

Jiggins, C. D., Naisbit, R. E., Coe, R. L., and Mallet, J. (2001). Reproductive isolation caused by colour pattern mimicry. Nature 411, 302-305. doi: 10.1038/35077075

Jungfer, K., Weygoldt, P., and Juraske, N. (1996). Dendrobates vincentei, ein neuer Pfeilgiftfrosch aus Zentral Panama. Herpetofauna 18, 17-26.

Kodric-Brown, A., and Strecker, U. (2001). Responses of Cyprinodon maya and Clabiosus females to visual and olfactory cues of conspecific and heterospecific males. Biol. J. Linn. Soc. 74, 541-548. doi: 10.1006/bijl.2001.0598

Maan, M. E., and Cummings, M. E. (2008). Female preferences for aposematic signal components in a polymorphic poison frog. Evolution 62, 2334-2345. doi: 10.1111/j.1558-5646.2008.00454.x

Maan, M. E., and Cummings, M. E. (2009). Sexual dimorphism and directional sexual selection on aposematic signals in a poison frog. Proc. Natl. Acad. Sci. U.S.A. 106, 19072-19077. doi: 10.1073/pnas.0903327106

Maan, M. E., and Cummings, M. E. (2012). Poison frog colors are honest signals of toxicity, particularly for bird predators. Am. Nat. 179, E1-E14. doi $10.1086 / 663197$

Maan, M. E., and Seehausen, O. (2011). Ecology, sexual selection and speciation. Ecol. Lett. 14, 591-602. doi: 10.1111/j.1461-0248.2011.01606.x

Meuche, I., Brusa, O., Linsenmair, K. E., Keller, A., and Prohl, H. (2013). Only distance matters - non-choosy females in a poison frog population. Front. Zool. 10:29. doi: 10.1186/1742-9994-10-29

Meuche, I., Linsenmair, K. E., and Prohl, H. (2011). Female territoriality in the strawberry poison frog (Oophaga pumilio). Copeia, 351-356. doi: 10.1643/ce08-135 
Milinski, M., and Bakker, T. C. M. (1990). Female sticklebacks use male coloration in mate choice and hence avoid parasitized males. Nature 344, 330-333. doi: 10.1038/344330a0

Narins, P. M., Hodl, W., and Grabul, D. S. (2003). Bimodal signal requisite for agonistic behavior in a dart-poison frog, Epipedobates femoralis. Proc. Natl. Acad. Sci. U.S.A. 100, 577-580. doi: 10.1073/pnas.0237165100

Noh, S., and Henry, C. S. (2009). Sexually monomorphic mating preferences contribute to premating isolation based on song in European green lacewings. Evolution 64, 261-270. doi: 10.1111/j.1558-5646.2009.00828.x

Panhuis, T. M., Butlin, R., Zuk, M., and Tregenza, T. (2001). Sexual selection and speciation. Trends Ecol. Evol. 16, 364-371. doi: 10.1016/s0169-5347(01)02160-7

Partan, S. R., and Marler, P. (2005). Issues in the classification of multimodal communication signals. Am. Nat. 166, 231-245. doi: 10.1086/431246

Prohl, H. (2002). Population differences in female resource abundance, adult sex ratio, and male mating success in Dendrobates pumilio. Behav. Ecol. 13, 175-181. doi: 10.1093/beheco/13.2.175

Prohl, H., and Berke, O. (2001). Spatial distributions of male and female strawberry poison frogs and their relation to female reproductive resources. Oecologia 129, 534-542. doi: 10.1007/s004420100751

Prohl, H., Eulenburg, J., Meuche, I., and Bolaños, F. (2013). Parasite infection has little effect on sexual signals and reproductive behaviour in strawberry poison frogs. Evol. Ecol. 27, 675-692. doi: 10.1007/s10682-013-9634-2

Prohl, H., Hagemann, S., Karsch, J., and Hobel, G. (2007). Geographic variation in male sexual signals in strawberry poison frogs (Dendrobates pumilio). Ethology 113, 825-837. doi: 10.1111/j.1439-0310.2007.01396.x

Prohl, H., and Hodl, W. (1999). Parental investment, potential reproductive rates, and mating system in the strawberry dart-poison frog, Dendrobates pumilio. Behav. Ecol. Sociobiol. 46, 215-220. doi: 10.1007/s002650050612

Prohl, H., and Ostrowski, T. (2011). Behavioural elements reflect phenotypic colour divergence in a poison frog. Evol. Ecol. 25, 993-1015. doi: 10.1007/s10682-0109455-5

Ptacek, M. B. (2000). The role of mating preferences in shaping interspecific divergence in mating signals in vertebrates. Behav. Processes 51, 111-134. doi: 10.1016/s0376-6357(00)00123-6

Ratcliffe, L. M., and Grant, P. R. (1985). Species recognition in Darwin's finches (Geospiza, Gould). III. Male responses to playback of different song types, dialects and heterospecific songs. Anim. Behav. 33, 290-307. doi: 10.1016/s00033472(85)80143-3

R Developmental Core Team. (2012). R: A Language and Environment for Statistical Computing. Vienna: R Foundation for Statistical Computing.

Reynolds, R. G., and Fitzpatrick, B. M. (2007). Assortative mating in poison-dart frogs based on an ecologically important trait. Evolution 61, 2253-2259. doi: 10.1111/j.1558-5646.2007.00174.x

Richards-Zawacki, C. L., Wang, I. J., and Summers, K. (2012). Mate choice and the genetic basis for colour variation in a polymorphic dart frog: inferences from a wild pedigree. Mol. Ecol. 21, 3879-3892. doi: 10.1111/j.1365-294X.2012.05644.x

Rundle, H. D., and Nosil, P. (2005). Ecological speciation. Ecol. Lett. 8, 336-352. doi: 10.1111/j.1461-0248.2004.00715.x

Ryan, M. J., and Rand, A. S. (1993). Species recognition and sexual selection as a unitary problem in animal communication. Evolution 47, 647-657. doi: $10.2307 / 2410076$
Sobel, J. M., Chen, G. F., Watt, L. R., and Schemske, D. W. (2010). The biology of speciation. Evolution 64, 295-315. doi: 10.1111/j.1558-5646.2009. 00877.x

Sullivan, B. K., Ryan, M. J., and Verrel, P. A. (1995). "Female choice and mating system structure," in Amphibian Biology, eds H. Heatwole and B. K. Sullivan (Chipping Norton: Surrey Beatty \& Sons), 469-517.

Summers, K., Bermingham, E., Weigt, L., and McCafferty, S. (1997). Phenotypic and genetic divergence in three species of dart-poison frogs with contrasting parental behavior. J. Hered. 88, 8-13.

Summers, K., Cronin, T. W., and Kennedy, T. (2003). Variation in spectral reflectance among populations of Dendrobates pumilio, the strawberry poison frog, in the Bocas del Toro Archipelago, Panama. J. Biogeogr. 30, 35-53. doi: 10.1046/j.1365-2699.2003.00795.x

Summers, K., Symula, R., Clough, M., and Cronin, T. (1999). Visual mate choice in poison frogs. Proc. Biol. Sci. 266, 2141-2145.

Taylor, R. C., Buchanan, B. W., and Doherty, J. L. (2007). Sexual selection in the squirrel treefrog Hyla squirella: the role of multimodal cue assessment in female choice. Anim. Behav. 74, 1753-1763. doi: 10.1016/j.anbehav.2007.03.010

Uy, J. A. C., Moyle, R. G., and Filardi, C.E. (2009). Plumage and song differences mediate species recognition between incipient flycatcher species of the Solomon Islands. Evolution 63, 153-164. doi: 10.1111/j.1558-5646.2008.00530.x

Wang, I. J., and Shaffer, H. B. (2008). Rapid color evolution in an aposematic species: a phylogenetic analysis of color variation in the strikingly polymorphic strawberry poison-dart frog. Evolution 62, 2742-2759. doi: 10.1111/j.15585646.2008.00507.x

Wilkins, M. R., Seddon, N., and Safran, R. J. (2013). Evolutionary divergence in acoustic signals: causes and consequences. Trends Ecol. Evol. 28, 156-166. doi: 10.1016/j.tree.2012.10.002

Wong, R. Y., So, P., and Cummings, M. E. (2011). How female size and male displays influence mate preference in a swordtail. Anim. Behav. 82, 691-697. doi: 10.1016/j.anbehav.2011.06.024

Zeyl, J. N., and Laberge, F. (2011). Multisensory signals trigger approach behaviour in the fire-bellied toad Bombina orientalis: sex differences and call specificity. Zoology 114, 369-377. doi: 10.1016/j.zool.2011.08.001

Conflict of Interest Statement: The authors declare that the research was conducted in the absence of any commercial or financial relationships that could be construed as a potential conflict of interest.

Received: 11 March 2014; accepted: 19 May 2014; published online: 05 June 2014. Citation: Dreher CE and Pröhl H (2014) Multiple sexual signals: calls over colors for mate attraction in an aposematic, color-diverse poison frog. Front. Ecol. Evol. 2:22. doi: $10.3389 /$ fevo.2014.00022

This article was submitted to Behavioral and Evolutionary Ecology, a section of the journal Frontiers in Ecology and Evolution.

Copyright (C) 2014 Dreher and Pröhl. This is an open-access article distributed under the terms of the Creative Commons Attribution License (CC BY). The use, distribution or reproduction in other forums is permitted, provided the original author(s) or licensor are credited and that the original publication in this journal is cited, in accordance with accepted academic practice. No use, distribution or reproduction is permitted which does not comply with these terms. 